\title{
INCIDENCE AND DIFFERENT RISK FACTORS OF CARDIAC SURGERY ASSOCIATED ACUTE KIDNEY INJURY
}

\author{
Lubna Shaheen, Amna*, Syed Shaheer Haider Bukhari**, Rehana Javaid*, Rashad Sidiqui* \\ Queen Elizabeth Hospital Birmingham UK, *Armed Forces Institute of Cardiology/National Institute of Heart Disease \\ (AFIC/NIHD)/National University of Medical Sciences (NUMS) Rawalpindi Pakistan, **Hameed Latif Hospital Lahore Pakistan
}

\section{ABSTRACT}

Objective: To identify the incidence of cardiac surgery associated acute kidney injury and its association with different risk factors.

Study Design: Descriptive cross sectional study.

Place and Duration of Study: Adult cardiac surgery department, AFIC/NIHD, from Jan to Jun 2019.

Methodology: Three hundred forty patients undergoing cardiac surgery were evaluated for Cardiac Surgery associated acute kidney injury according to acute kidney injury network criteria over a period of 6 months. The chi-square test was used find the relationship of different factor for cardiac surgery associated acute kidney injury.

Results: Total of 430 patients were included. 345 (80.2\%) were male and mean age of $55 \pm 11.6$ years and mean pre operative creatinine clearance was $80.7 \mathrm{ml} / \mathrm{hr}$. Coronary artery bypass grafting was the most common procedure performed. Intra aortic balloon pump, Cardio-pulmonary bypass time, AXc time, ionotropes, transfusion of RCC and FFPs were found to be highly significant risk factors of acute kidney injury.

Conclusion: Cardiac surgery associated acute kidney injury is very common complication; some of the modifiable factors should be identified and controlled to reduce acute kidney injury.

Keywords: Aortic cross clamp time, Cardiac surgery associated acute kidney injury, Cardio pulmonary bypass time, IABP, Risk factors, Transfusions.

This is an Open Access article distributed under the terms of the Creative Commons Attribution License (http://creativecommons.org/licenses/by/4.0), which permits unrestricted use, distribution, and reproduction in any medium, provided the original work is properly cited.

\section{INTRODUCTION}

Cardiac surgery is associated with many complications, Cardiac Surgery Associated Acute kidney Injury (CSA-AKI) is one of the common complications after cardiac surgery. CSA-AKI is one of the strongest predictor of mortality after cardiac surgery, and of the serious postoperative complication leading to prolong recovery period ${ }^{1}$.

Variable factors have been identified by numerous different studies ${ }^{2}$. There is a complex relationship between patient demographic factors and surgery related factors such as Cardio-pulmonary bypass time, Aortic cross clamp time $(\mathrm{ACx})$, multiple transfusions, ionotropes, intra aortic balloon pump (IABP), vasopressor scan be attributed to the development of AKI postoperatively ${ }^{1-3}$. Baseline co-morbidities such as

Correspondence: Dr Amna, Department of Cardiac Anesthesia, AFIC/NIHD Rawalpindi Pakistan diabetes mellitus, congestive cardiac failure, and preexisting chronic kidney disease and functional status are very important factors likely to predispose patients in developing renal insult following cardiac procedures patients under-going cardiac surgery ${ }^{4-6}$.

Some of the modifiable risk factors such as $\mathrm{CPB}$ time and $\mathrm{ACx}$ time have got significant effect on development of post cardiac surgery AKI. In one of the study increasing cardio-pulmonary bypass time and aortic cross clamp time increases risk with $p$-value of $0.00^{7,8}$.

The incidence of AKI varies depending on various classification varies from 5 to $43 \%$, with 1 to $7 \%$ of the patients require dialysis ${ }^{9,10}$. Even modest kidney injury is independently associated with markedly increased morbidity and mortality. A retrospective study was carried out to examine various risk factors associated with CSAAKI. 


\section{METHODOLOGY}

It was a descriptive cross sectional study carried out retrospectively at cardiac surgery intensive care unit (ICU) of Armed Forces Institute of Cardiology Rawalpindi (AFIC). Study was completed in a minimum of six month after approval of synopsis from institutional ethics review board of hospital. Consecutive non probability sampling technique was used. Inclusion criteria comprised of patients with age greater than 20 years, all open heart surgical procedure, absence of any kidney pathology and creatinine clearance greater than $60 \mathrm{ml} / \mathrm{min}$ were included. Exclusion Criteria comprised of any known case of kidney disease, patient on renal replacement therapy, serum creatinine $>2 \mathrm{mg} / \mathrm{dl}$ creatinine clearance less than $60 \mathrm{ml} / \mathrm{min}$, redo surgeries and aortic root aneurysm surgeries.

After approvalby the ethical committee of our institute, consecutive patients undergoing cardiac surgery were studied in cardiac surgery ICU lasting 06 months. Demographic details, preoperative evaluation including comorbidsdetails, disease, premedication, anesthesia and surgery details were collected from cardiac anesthesia and ITC data base proforma filled by assistant and data collection team. Data base performa along with ICU monitoring charts were evaluated
Data was analyzed using statistical package for social science (SPSS) version 20.0. (spss v20.0). CSA-AKI incidence and severity was determined and classified using AKIN criteria and expressed in absolute number and percentages. Off Pump cases were also identified and including for data stratification, cardiopulmonary bypass time and aortic cross clamp time was recorded and grouped further $t$ i.e. $<70,70-140,>140$ minutes and $<50,50-80,>80$ minutes. Acute Kidney Injury Network (AKIN) criteria described acute kidney injury in terms of three stages using serum creatinine and urine output criteria ${ }^{11}$. It was formed in September 2004.

\section{RESULTS}

The study included a total of 430 patients. $345(80.2 \%)$ were male and $85(19.8 \%)$ were female. Mean and standard deviation for age and weight of patients was $55 \pm 11.6$ years and 72.4 $\pm 12.5 \mathrm{~kg}$ (Mean $\pm \mathrm{SD}$ ) respectively. Minimum age of patients presented for surgery was 22 years and minimum weight was $35 \mathrm{~kg}$. Mean pre operative creatinine clearance was $80.77 \mathrm{ml}$ per hour. Most of the patients underwent coronary artery bypass grafting (CABG) percentages of other group of cardiac surgery is given in the table-II.

In our study 132 (30.6\%) patients were smoker, while diabetes and hypertension were found

Table-I: Acute kidney injury network criteria (AKIN).

\begin{tabular}{c|l|l}
\hline Stage & Serum Creatinine Criteria & Urine Out Criteria \\
\hline 1 & $\begin{array}{l}\text { Creatinine } \times 1.5-2.0 \text { from baseline OR: Creatinine Increased by at } \\
\text { least } 26.4 \mu \mathrm{mol} / \mathrm{L}\end{array}$ & $<0.5 \mathrm{ml} / \mathrm{kg} / \mathrm{hr} \times 6 \mathrm{hrs}$ \\
\hline 2 & Creatinine $\times 2.0-3.0$ & $<0.5 \mathrm{ml} / \mathrm{kg} / \mathrm{hr} \times 12 \mathrm{hrs}$ \\
\hline 3 & $\begin{array}{l}\text { Creatinine } \times 2.0-3.0 \mathrm{OR} \\
\text { Creatinine over } 354 \mu \mathrm{mol} / \mathrm{L}, \text { with an acute increase by at least } 44 \\
\mu \text { mol/L OR: The initiation of RRT }\end{array}$ & $\begin{array}{c}<0.3 \mathrm{ml} / \mathrm{kg} / \mathrm{hr} \times 24 \mathrm{hrs} \\
\text { OR } \\
\text { Anuria for } 12 \mathrm{hrs}\end{array}$ \\
\hline
\end{tabular}

to collect information regarding, urine output, serum creatinine, ICU stay, need for dialysis and Continuous renal replacement therapy, and mortality. CSA-AKI to be determined using Acute Kidney Injury Network (AKIN) Criteria. All patients were assessed for risk stratification and diagnosis of post-operative acute kidney injury by the investigators. in $40.7 \%$ and $58.2 \%$ respectively. According to AKIN criteria 253 (58.9\%) of the patient was found to have some degree of kidney injury. IABP insertion was done in 67 (15.6\%) patients. Regarding transfusion, Red cell concentrates (RCC) and fresh frozen plasma (FFPs) were transfused to 279 $(64.8 \%)$ and $126(29.3 \%)$ required respectively, only $27(6.3 \%)$ required greater than 05 units of 
RCC. In 49 (11.6\%) of patients high ionotropic supports were required and $84(19.5 \%)$ patients had prolonged ICU stay i.e greater than 48 hours. $14(3.3 \%)$ out of 430 patients unfortunately died.

Out of 430, most of the patients 190 (44.2\%)developed class 1 and 54 (12.6\%) patients had class 2 kidney injury; only 9 (2.1\%) patients develop class 3 kidney injury requiring Conti-

Table-II: Frequency and percentage of different cardiac surgeries.

\begin{tabular}{l|c}
\hline Procedures n $=\mathbf{4 3 0}$ & $\mathbf{n ~ ( \% )}$ \\
\hline On Pump CABG & $87(64.6)$ \\
\hline On Pump CABG & $277(64.4)$ \\
\hline Mitral Valve Surgery & $21(4.9)$ \\
\hline Aortic valve Surgery & $23(5.3 .0)$ \\
\hline Double Valve Surgery & $19(4.4$ \\
\hline CABG plus Valve Surgery & $3(0.7)$ \\
\hline
\end{tabular}

Table-III: Post operative AKI according to severity.

\begin{tabular}{l|c}
\hline Stage of AKI & $\mathbf{n ~ ( \% )}$ \\
\hline 1 & $190(44.2)$ \\
\hline 2 & $54(12.6)$ \\
\hline 3 & $9(2.1)$ \\
\hline
\end{tabular}

Table-IV: $p$-values of Different Clinical Factors.

\begin{tabular}{c|l|c}
\hline S.No. & Factors & $\boldsymbol{p}$-value \\
\hline 1 & CPB time & 0.00 \\
\hline 2 & AXc time & 0.00 \\
\hline 3 & IABP & 0.00 \\
\hline 4 & Smoking & 0.20 \\
\hline 5 & Hypertension & 0.99 \\
\hline 6 & Diabetes Mellitis & 0.70 \\
\hline 7 & RCC & 0.00 \\
\hline 8 & FFPs & 0.00 \\
\hline 9 & Ionotropes & 0.00 \\
\hline 10. & Gender & 0.92 \\
\hline
\end{tabular}

nuous Renal Replacement Therapy (CRRT) out of which 7 (1.6\%) were male. 254 (59.1\%) of the male patients while $247(57.6 \%)$ of females had AKI post cardiac surgery. Blood and blood products, Cardio pulmonary bypass time, IABP, and high ionotropes were found to be the significant risk factors with $p$-value of 0.00 . AKI was highly associated with mortality and prolong icu stay with $p$ value of 0.00 as shown in table-IV.

\section{DISCUSSION}

In Our retrospective observational study, CSA-AKI was to be present in 430 patients; inci- dence and risk stratification was done. In the present study, $253(58.9 \%)$ of the patients were found to develop acute kidney injury, which is relatively higher as compared to other studies and reviews 4 . In our study Acute Kidney Injury Network (AKIN) was used, that was based on an increase in serum creatinineby $0.3 \mathrm{mg}$ dL-1 (26.2 $\mu$ mol L-1) during a $48 \mathrm{~h}$ period ${ }^{12}$. The AKIN criteria have shown to diagnose significantly more patients as having AKI as compared to risk, injury, failure, loss of kidney function, and end stage renal failure (RIFLE) ${ }^{12}$.

Several potential risk factors have been identified causing CSA-AKI, including Comorbids diabetes mellitus, Hypertension and older age, smoking, elevated baseline creatinine, intraoperative factors like $\mathrm{CPB}$ time, use of inotropic drugs, transfusions of blood and products13,14. Factors evaluated in our surgery were, Gender, co-morbids included DM, hypertension and smoking, CPB time, off pump cases, AXc time, RCC and FFPs transfusion, ionotropic requirement and IABP. We also studied frequency of different AKIN class, ICU stay and mortality. Among the factors studied, CPB time, AXc time, RCC and FFPs transfusion, ionotropic requirement and IABP were the most significant factors that cause AKI.

Coronary bypass grafting (CABG) was the predominant surgery performed in our study 364 $(84.7 \%)$ as compared to valve replacement surgeries, that is also a known independent risk factor for development of CSA-AKI ${ }^{15}$. In this study CPB time is one of the most significant factors with $p$ value of 0.00. Risk of kidney injury increases with rise in $\mathrm{CPB}$ time and $\mathrm{AXCtime}$ as described by meta-analysis by kumar et al16, and other studies ${ }^{8}$. A comparison of off-pump and on-pump cardiac surgery with respect to kidney injury was evaluated in a Meta analysis of randomized trials ${ }^{17}$. In our study out of 87 (20.0\%) off pump surgeries 13 $(14.9 \%)$ patients develop kidney injury but none of them required dialysis or renal replacement therapy. Large randomized controlled trials coronary compared off-pump and on pump CABG 
surgery and found no significant effect on new onset kidney injury requiring dialysis ${ }^{18}$.

The risk of AKI increases with increase in peri operative RCC and FFPs transfusions, a study showed that in patients with anemia undergoing cardiac surgery risk of AKI increased to twice because of receiving perioperative transfusions of red cell concentrate (RCC) as compared to those who required no transfusions ${ }^{19,20}$. A positive correlation was observed between the number of RCC units transfused and the incidence of AKI. While in other studies risk of death and complications is comparable to liberal transfusion versus restrictive ${ }^{21}$.

Other factors like use of IABP and ionotropes in post operative period increase incidence of AKI and mortality, According to a 6 year experience of a Single centre AKI after cardiac surgery predictors related to mortality were IABP and resternotomy ${ }^{22}$. In another study factor causing AKI were almost same as in our research they included CPB time, transfusion, ionotropes and $\mathrm{IABP}^{23}$.

\section{CONCLUSION}

Risk of CSA-AKI is very common complication; it is related to many risk factors. Most common is AKIN Class I, high incidence in our study might be due to criteria used in our study. IABP, CPB time, AXc time, ionotropes, Transfusion of RCC and FFPs are significant risk factors of acute kidney injury. The AKIN can be identified earlier and can be prevented by decreasing cardiopulmonary bypass time and aortic cross clamp time and prevent transfusions.

\section{CONFLICT OF INTEREST}

This study has no conflict of interest to be declared by any author.

\section{REFERENCES}

1. O'Neal JB, Shaw AD, Billings FT. Acute kidney injury following cardiac surgery: current understanding and future directions. Critical Care 2016; 20(1): 187-90.

2. Parolari A, Pesce LL, Pacini D, Mazzanti V, Salis S, Sciacovelli C, et al. Monzino Research Group on Cardiac Surgery Outcomes. Risk factors for perioperative acute kidney injury after adult cardiac surgery: role of perioperative management. Ann Thorac Surg 2012; 93(2): 584-91.
3. Rosner $\mathrm{MH}$, Okusa MD. Acute kidney injury associated with cardiac surgery. Clin J Am Soc Nephrol 2006; 1(1): 19-32.

4. Hertzberg U, Sartipy MJ. Holzmann, Type 1 and type 2 diabetes mellitus andrisk of acute kidney injury after coronary artery bypass grafting. Am Heart J 2015; 170(5): 895-02.

5. Amer H, Joshi M, Shubhi G, Wan YT, Francesca G, Mostafa S. Acute Kidney Injury Associated with Cardiac Surgery: a Comprehensive Literature Review. Braz J Cardiovasc Surg 2020; 35(2): 211-24.

6. Wijeysundera DN, Karkouti K, Dupuis JY, Rao V, Chan CT, Granton JT, et al. Derivation and validation of a simplified predictive index for renalreplacement therapy after cardiac surgery. J Am Med Assoc 2007; 297(16): 1801-09.

7. Lassnigg A, Schmidlin D, Mouhieddine M, Bachmann LM, Druml W, Bauer P, et al. Minimal changesof serum creatinine predict prognosis in patients aftercardiothoracic surgery: a prospective cohort study. J Am Soc Nephrol 2004; 15(6): $1597-60$

8. Amna H, KItizaz S, Karam AZ. Iftikhar J. Cardiac Surgery Associated Acute Kidney Injury in relation to Cardiopulmonary bypass time and Aortic cross clamp time; Pak Arm For Med J 2018; 68(Suppl-1): 839-45

9. Hobson CE, Yavas S, Segal MS, Schold JD, Tribble CG, Layon $\mathrm{AJ}$, et al. Acute kidney injury is associated with increased longterm mortality after cardiothoracic surgery. Circulation 2009; 119(18): 2444-53.

10. Lagny MG, Jouret F, Koch JN, Blaffart F, Donneau AF, Albert A, et al. Incidence and outcomes of acute kidney injury after cardiac surgery using either criteria of the RIFLE classification. BMC Nephrol 2015; 16(1): 76-84.

11. Mehta RL, Kellum JA, Shah SV, Molitoris BA, Ronco C, Warnock DG, et al. Acute Kidney Injury Network: report of an initiative to improve outcomes in acute kidney injury. Crit Care 2007; 11(2): R31

12. Englberger L, Suri RM, Li Z, Casey ET, Daly RC, Dearani JA, et al. Clinical accuracy of RIFLE and Acute Kidney Injury Network (AKIN) criteria for acute kidney injury in patients undergoing cardiac surgery. Crit Care 2011; 15(1): R16.

13. Parolari A, Pesce LL, Pacini D. Monzino Research Group on Cardiac Surgery Outcomes: Risk factors for perioperative acute kidney injury after adult cardiac surgery: role of perioperative management. Ann Thorac Surg 2012; 93(1): 584-91.

14. Brown JR, Kramer RS. Determinants of acute kidney injury duration after cardiac surgery: an externally validated tool. Ann Thorac Surg 2012; 93(2): 570-76.

15. Karim HM, YunusM, Saikia MK, Kalita JP, Mandal M. Incidence and progression of cardiac surgery associated acute kidney injury and its relationship with bypass and cross clamp time. Ann Card Anaesth 2017; 20(1): 22-27.

16. Kumar AB, Suneja M, Bayman EO, Weide GD, Tarasi M. Association between postoperative acute kidney injury and duration of cardiopulmonary bypass: a meta-analysis. J Cardiothorac Vasc Anesth 2012; 26(1): 64-69.

17. Seabra VF, Alobaidi S, Balk EM. Off-pump coronary artery bypass surgery and acute kidney injury: a meta-analysis of randomized controlled trials. Clin J Am SocNephrol 2010; 5(1): e1734-e44.

18. Garg AX, Devereaux PJ, Yusuf S. Coronary Artery Bypass Grafting Surgery Off- or On-pump Revascularisation Study (CORONARY): kidney substudy analytic protocol of an international randomised controlled trial. BMJ Open 2012; 2(1): e001080.

19. Karkouti K, Wijeysundera DN, Yau TM. Advance targeted transfusion in anemic cardiac surgical patients for kidney 
protection: an unblinded randomized pilot clinical trial. Anesthesiol 2012; 116(1): 613-21.

20. Karkouti K, Wijeysundera DN, Yau TM. Acute kidney injury after cardiac surgery: focus on modifiable risk factors. Circulation 2009; 119(2): 495-02.

21. Hajjar LA, Vincent JL, Galas FR. Transfusion requirements after cardiac surgery: the TRACS randomized controlled trial. J Am Med Assoc 2010; 304(1): 1559-67.
22. Kowalik MM, Lango R, Klajbor K. Incidence and mortalityrelatedrisk factors of acute kidney injury requiring hemofiltration in patientsundergoing cardiac surgery: a single-center 6-year experience. J Cardiothorac Vasc Anesth 2011; 25(1): 619-22.

23. Parolari A, Pesce LL, Pacini D. Risk factors for perioperative acute kidneyinjury after adult cardiac surgery: role of perioperative management. Ann Thorac Surg 2012; 93(2): 584-91. 